\title{
PRODUCTION OF COCONUT OIIL DIRECTLY FROM FRESH COCONUT MEAT USING THE WASTE HEAT RECOVERY TECHNOLOGY: A "NEW OIL PROCESS"
}

\author{
By \\ By G. R. Breag, P. Drew and P. G. Joseph ${ }^{1}$
}

\begin{abstract}
SUMMARY
In several, areas, in Sri Lanka the use of pits for making coconut shell charcoal is restricted or not permitted due to environmental damage or the proximity of human habitation. In addition approximately $50 \%$ of the gross heat content of the shells is lost to the surroundings during the process. In view of the above, the Natural Resources Institute developed a coconut shell carbonization unit with waste heat recovery, which virtually eliminates the smoke problem and simultaneously enables the heat generated during the process-heat normally lost to the surroundings to be used as process heat in the coconut industry. This technology has been commercialized in Sri Lanka and details of the standard capacity (1.5 tonnes shell) unit and its performance are provided. The findings of preliminary trials carried out on the application of the waste heat recovery technology in the production of coconut oil from freshly decorticated macerated coconut meat - bypassing copra production-are also discussed. The technical and financial aspects of the application of the technology for coconut oil manufacture using the "new oil process" in Sri Lanka are briefly covered and consideration for its adoption in other coconut growing countries is recommended.
\end{abstract}

\section{INTRODUCTION}

Coconut oil is used for cooking purposes, in margarine manufacture and as a feedstock for soap production. It is produced in Sri Lanka and many other coconut producing countries - for local consumption and export - by pressing copra, the dried coconut kernel. The oil is extracted under pressure using continuous screw expellers or band and hydraulic presses for small-scale batch production. The copra cake is used for animal feed.

The quality of the oil and copra cake produced largely depends on the quality of the copra used. Generally the copra is of relatively poor quality, due primarily to poor sun-and/or smoke-drying methods. The manufacture of oil from freshly cut and dried coconut meat, bypassing copra manufacture, offers a means of producing better quality oil with a low free fatty acid content and light colour. In addition the cake and oil produced using indirect drying of the meat and subsequent extraction of oil would be free of aflatoxin and polyaromatic hydrocarbon (PAH) contamination.

For the above reasons coconut oil has to some extent already been manufactured directly from macerated fresh cut coconut meat. For example: (a) CeCoCo (CeCoCo 1968) have offered an oil expelling plant consisting basically of a steam boiler, high pressure cooker, oil expeller and. filter press system; (b) a similar type of system using a rotary dryer known as the Katigbak system after the developer, was operated in the Philippines (Internal communication). Another oil extraction process, where the fresh cut coconut meat is dried in hot coconut oil prior to oil extraction, is in use in Indonesia. A survey of the extent of use of these types of oil extraction systems using fresh coconut meat was not carried out, but (a) and (b) are known not to be in widespread use. On the other band there are a number of locations in Indonesia where the "fry-dry" method is employed.

\footnotetext{
${ }^{1}$ Head of Process and Storage Engineering Department, NRI, Chemical Engineer ODA assigned to CDA/NRI collaborative Coconut Project, Sri Lanka, Energy Engineer, CDA, Sri Lanka, respectively.
} 
Recognizing the advantages of bypassing copra for coconut oil production, the Natural Resources Institute (NRI) ${ }^{2}$ in collaboration with the Coconut Development Authority (CDA) in Sri Lanka worked on the production of coconut oil from fresh cut coconut meat. The approach adopted was to use the waste heat generated during the carbonization of coconut shell to dry the freshly cut kernels prior to oil extraction, by employing the waste heat recovery unit (WHU) technology developed by NRI. In addition, in the study equipment customarily used in local oil extraction was adapted for the process.

The following account describes the traditional charcoal production method used in Sri Lanka, the VMU technology and its application to the production of coconut oil from fresh kernels henceforth referred to as the "new oil" process. The technical and financial aspects on the use of the technology are also briefly covered.

\section{CHARCOAL PRODUCTION}

\section{The Traditional Pit Method of Charcoal Production}

The traditional pit method of charcoal production yields approximately $30 \%$ of the dry weight of the shells used as feedstock. The charcoal produced is of variable quality and is often contaminated with extraneous matter and soil as a result of the methods employed.

During this process $50 \%$ of the gross heat content of the shells is lost to the surroundings. At the same time a large volume of obnoxious smoke is evolved and as a result, in several areas of Sri Lanka, the use of pits for charcoal-making is restricted or not permitted due to environmental damage or the proximity of human habitation. Consequently in many cases the process has to be carried out some distance from the factory where the shell is generated and this can entail the transport of shell for several miles. Details of the traditional pit charcoal production method is reported elsewhere (Breag et al 1985).

\section{Carbonization with Waste Heat Recovery Technology}

The coconut shell carbonization with waste heat recovery unit (WHU) as developed, reduces the smoke problem to a few minutes per day - at "start-up" - and produces clean, well-carbonized charcoal using coconut shell from desiccated coconut mills and copra kilns. The gas evolved during the carbonization is burned in a furnace producing process heat for application in the coconut industry. The shells therefore replace either imported fuel oil or locally felled wood. Application of the WHU technology consequently reduces deforestation. In addition it maximizes the utilization of shell feedstock for charcoal production. The latter statement is discussed further later. An important advantage is that the utilization of shell with the WHU gives the processor a greater degree of energy self-sufficiency.

\section{COMMERCIALISATION OF WHU-TECHNOLOGY}

The early development of the WHU and its scope for application was reported earlier (Breag et al 1985). This technology was successfully introduced into the commercial sector in Sri Lanka (Tillekeratne, 1989) through a collaborative programme of work between the CDA and NRI. The technical co-operation components of the programme were funded by the ODA via the South East Asian Development Division in Bangkok, and the cost of local staff and support services were met by the CDA. Technical, financial and economic information on the WHU-technology and its application in the Coconut Industry in Sri Lanka are given in the Report on the Regional Workshop on Waste Heat Recovery Technology in Coconut Processing held in Colombo, Sri Lanka in

\footnotetext{
${ }^{2}$ Footnote: NRI is the scientific arm of the United Kingdom's Overseas Development Administration (ODA).
} 
September 1989. This Workshop was held under the aegis of the Asian and Pacific Coconut Community (APCC), hosted by the Government of Sri Lanka and organized jointly by the CDA and NRI.

The technology was developed at two scales of batch operation: a standard capacity unit (1.5 tonnes of shell) and a scaled-up version (3.4 tonnes of shell). This paper deals with the former scale of operation only. Details of the larger unit are provided in the Proceedings of the Regional Workshop cited above.

\section{DESCREPTION OF STANDARD WHU (1.5 tone capacity)}

The system (see Figure 1) consists of a vertical cylindrical metal kiln (1) (made from 9.5 to 10 $\mathrm{mm}$ thick mild steel sheets) connected to a burner/furnace fitted with an exhaust gas fan: the fan induces combustion and secondary air into the furnace system.

The approximate capacity of the unit is $8 \mathrm{M}^{3}$. Two hatches (2) and (3) are provided: one at the top of the kiln for loading shells and the other near the base of the kiln for discharging the charcoal. The top hatch is fitted with a thin mild steel bursting disc which will rupture in the unlikely event of the gas in the kiln exploding. A large horizontal lid (4) is located at the top of the kiln and can be swung over the burst disc by a pulley mechanism (5) operated from ground level. Its use has not been necessary to date. The main kiln body is designed to withstand over twice the theoretical pressure build-up in the event of the stoichiometric gas/air mixture spontaneously combusting in the kiln.

The charcoal produced is supported by removable rods (6) that form a grid over the gas outlet port. Six air inlet ports (7) are equally spaced around the circumference of the kiln for lighting the charge. The metal pipes which protrude into the charge are fitted with cast iron sheaths to protect the ends of the pipes from the high combustion temperatures experienced at these points. The air inlet ports are flanged so that right-angled bend pipes, fitted with dampers for fine control of the flow of air into the kiln, can be swung into position after lighting. The inlets to the bends are fitted with perforated plates (8) so that they will direct any "blowback" downwards and contain the flame or hot char which may be ejected - albeit very occasionally.

The gas outlet is located at the base of the kiln (9) and is connected to the burner by a pipe (10) via a damper (11), condensation trap (12) and flame trap (13). The damper's function is to control the "kiln gas" flow to the furnace; but the main control after start-up is maintained by setting the damper air inlets to the furnace (14) and adjusting the flue damper (15) in the exhaust gas fan (16) line.

The gases are drawn into the furnace with combustion air and ignited by two cast iron (or ceramic) thimbles (17) which hold hot glowing charcoal which serves as a pilot light. The furnace and shell side of the heat exchanger are fitted with explosion doors which open at approximately 14 $\mathrm{kg} / \mathrm{M} 2$ of pressure. (Breag and Joseph, 1989).

The heat provided by the hot gases of combustion was used to heat the drying air for the semi-automatic dryer system used in the "new oil process" (see section entitled "WHU application in "new oil process"). 


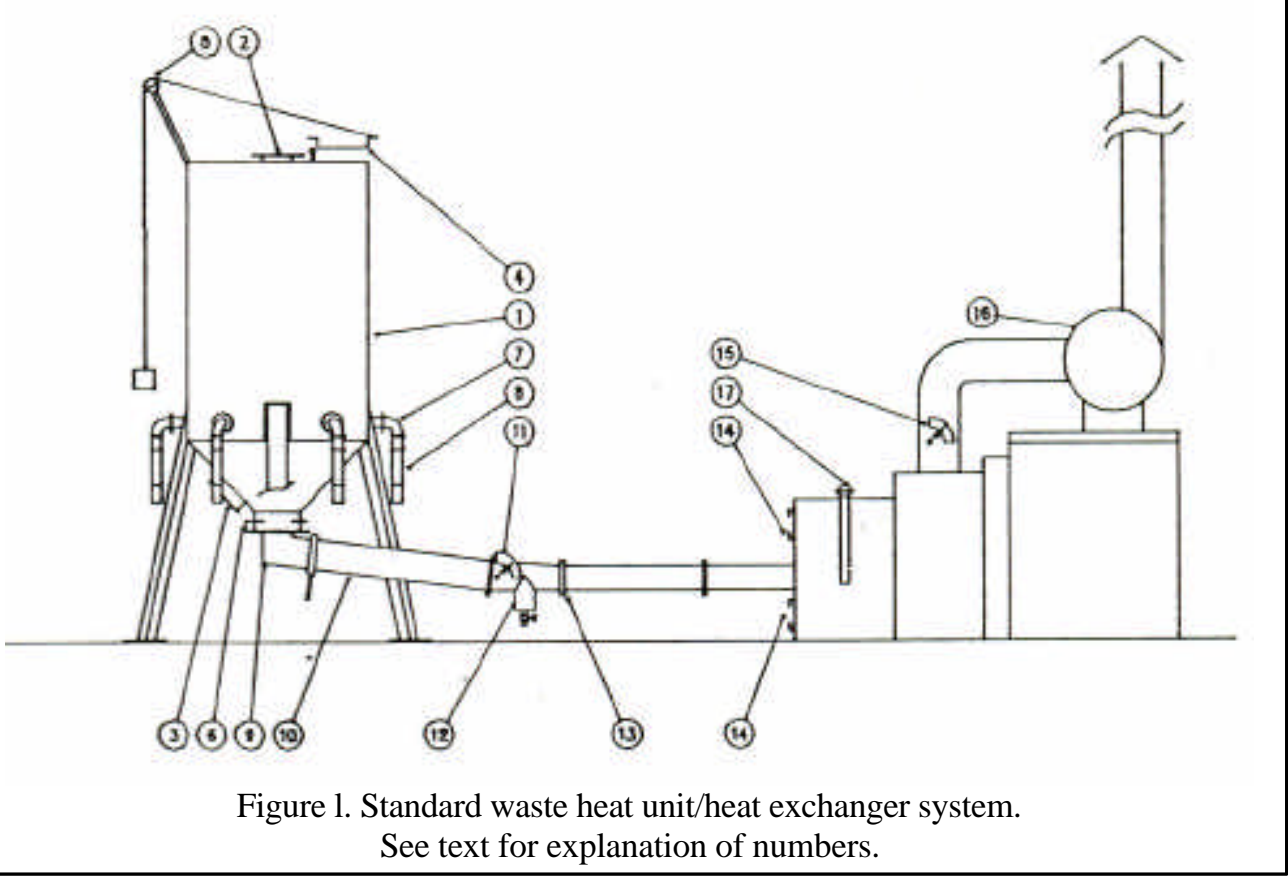

TRADITIONAL COPRA PRODUCTION

In Sri Lanka the bulk of copra production uses the traditional method where half-cups of coconut shell and meat are laid initially on concrete slabs to dry in the sun. They are then placed on platforms 2-3 meters above burning shells in sheds, and smoke-dried. The warm air and smoke produced pass through the trays of coconut cups by natural convection. Approximately $50 \%$ of the shells associated with the production of copra are used to fire the smoke kilns.

The time taken to produce copra, using the combined sun/smoke kiln drying method described above, is approximately 4 days. This drying period can be prolonged during rainy conditions.

It is important to note that the product quality obtained by this method is generally good but can be variable and poor for a variety of reasons such as bad weather and inadequate copra kiln operation in the production of milling grade copra. To produce good quality copra six to seven firings are necessary, but this consumes more shell and thus reduces the earnings of the producer, since surplus shells can be used to make charcoal or sold for commercial reasons. In Sri Lanka copra produced is of relatively good quality. However in much other copra producing countries the techniques employed are not as good and often husks and wood are used to smoke dry the copra using basic pits dug in the ground and mesh trays. The copra thus produced is often heavily smoked and "under-fired". This results in inadequately dried copra which is susceptible to mould attack and an increase in free fatty acid content. Many coconut oil producers complain of the quality of the copra and claim that in some cases the moisture content can be as high as 12 to $15 \%$. Nevertheless the high local demands for oil enable the copra producer to sell his product for milling in spite of variable and often poor quality. In an attempt to improve the efficiency of shell utilization and to avoid intermediate production of copra, studies were undertaken to evaluate the application of the WHU-technology in oil production using freshly cut coconuts."

The preliminary findings of the studies were favourable and are outlined on the following sections. 


\section{WHU APPLICATION IN "NEW OIL PROCESS"}

\section{Objectives:}

The main objective of the work was to assess the technical and financial advantages of producing coconut oil from fresh cut meat by avoiding copra production and using V;IHU technology. The likely advantages of this new method of oil production in Sri Lanka were considered to be: (A) the production of a good quality coconut cake and coconut oil with a low free fatty acid content, good colour and devoid of aflatoxin and polyaromatic hydrocarbon (PAH) contamination - such products would be sold at a premium; (B) a reduction in the risks to health of the consumers by eliminating aflatoxin and PAHs from the food chain; (C) maximizing utilization of the coconut shell by the production of good quality charcoal; (D) a reduction in the use of imported fuel oil; (E) a positive impact on the environment through efficient utilization of heat (heat normally lost to the surroundings), reduction in smoke pollution and alleviation in pressure on dwindling fuelwood resources; (F) increased foreign exchange earnings by the provision of more charcoal either for direct export or for local activated carbon manufacture.

\section{Current Oil Production Process}

In Sri Lanka copra is purchased or produced at the coconut factories. In small - to medium-scale oil mills the copra is cut into small pieces and fed to a semi-automatic dryer (described later) where it is dried down to approximately 46\% moisture content; it is then fed into the conditioning chamber of a continuous screw expeller. Following warming of the feedstock and sometimes the injection of steam, it is discharged into a hopper whence it is augered into the press. Depending on the mill, the oil is expelled either once or twice. Under good operating conditions over $94 \%$ of the oil in the copra can be expelled with a single pass through the expeller. The oil is then allowed to settle in tanks, filtered and subsequently pumped to storage tanks for collection and sale. The flow diagram of the current oil production system is given in Figure 2(a).

\section{The "New Oil Process"}

Prior to designing a WHU-fired dryer system for the manufacture of oil from freshly cut meat, preliminary trials were conducted at 3 oil mills. Using the standard wood-fired furnace/heat exchanger systems, the manpower requirements were determined and the technical feasibility of the "new oil process" from freshly cut kernels (separated from the shell by hatcheting) was evaluated. The techno-financial prognosis based on this preliminary data was favourable, the designs of a commercial WHU-fired oil mill were drawn up and a factory erected at Marawila Co-operative. The process flow diagram for the "new oil process" is given in Figure 2(b).

Dryer and heat exchanger system: a wood-fired furnace with a heat input of up to approximately one million $\mathrm{kJ} / \mathrm{h}$ was modified for operation on WHU "kiln gas". The hot combusted gases passed on the shell-side of the 80-tube heat exchanger dryer system, shown schematically in Figure 3. Ambient air was drawn through the tubes heated by the gases of combustion and blown into the semi-automatic dryer via a centrifugal fan. The drying air was then exhausted to atmosphere.

The semi-automatic dryer consisted basically of a chamber fitted with perforated trays through which cut copra or fresh coconut meat was passed. The material cascaded downwards, counter-currently to the flow of drying air, which entered at approximately 110 to $120^{\circ} \mathrm{C}$. 
Flow sheet

Flow diagrams showing comparison between the traditional and new oil process

Fresh split De-husked Nuts

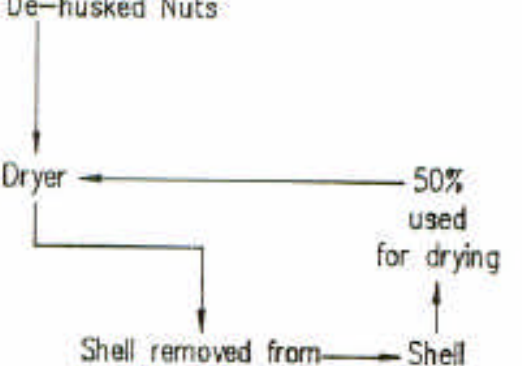

partially dried nuts
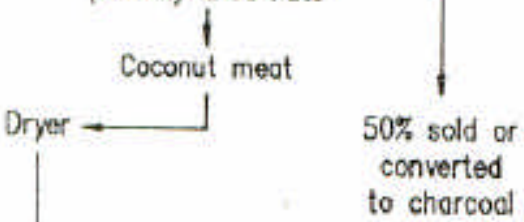

1

Copra

to charcoel

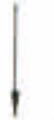

Tronsported

to oil mill

Fresh split De-husked Nuts

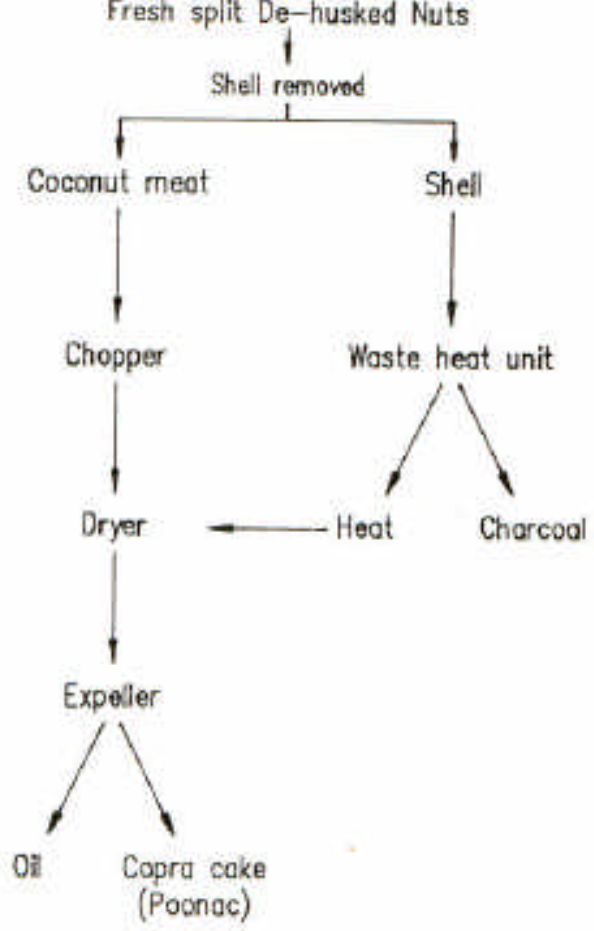

1

Chopper Wood of fuel oil

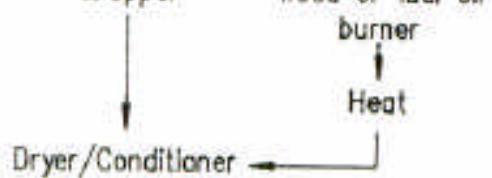

Dryer/Conditioner

$\mid$

Expeller

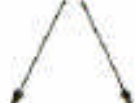

Oil Copra cake

(Poonoc)

Figure 2 (a) Traditional process.

Figure 2(b) New oil process 


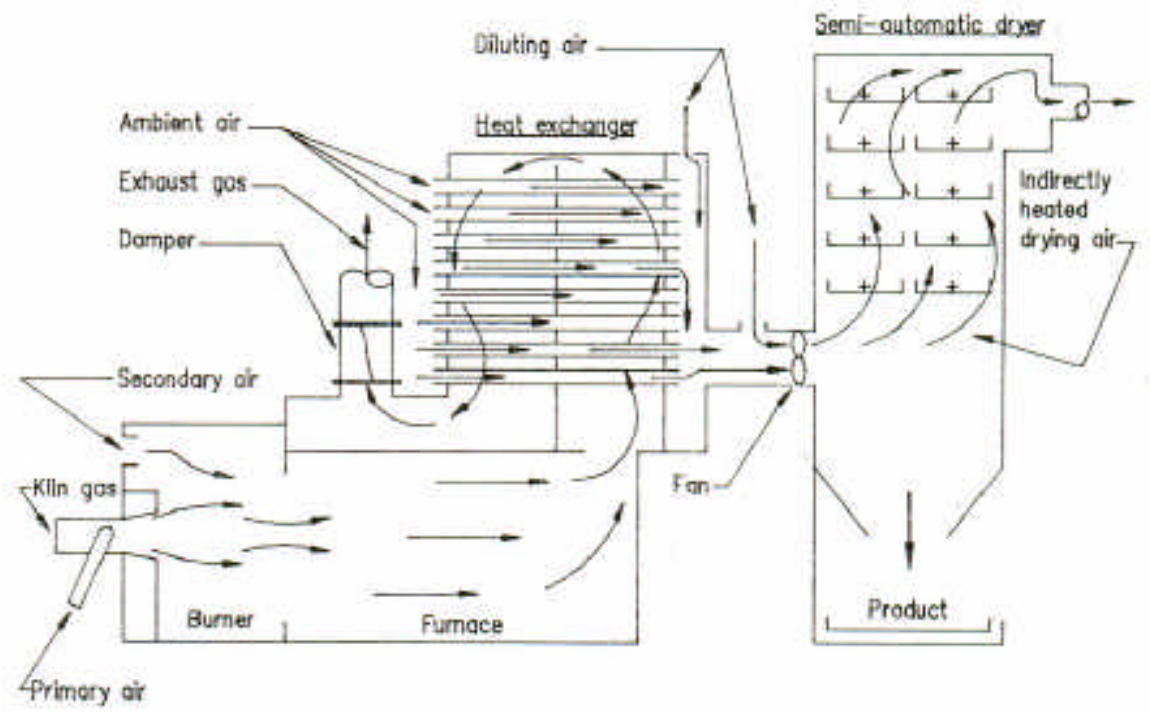

Figure 3. Gas and air flow (schematic) of furnace and dryer system.

Performance: The output of the dryer based on a fresh feed moisture content of $45 \%$ ranged from 120 to $160 \mathrm{~kg} / \mathrm{h}$ of dried coconut meat at approximately $4 \%$ moisture content.

Typical results on the overall heat and mass balance using a WHU/ Semi-automatic dryer system are summarized in Figure 4 below.

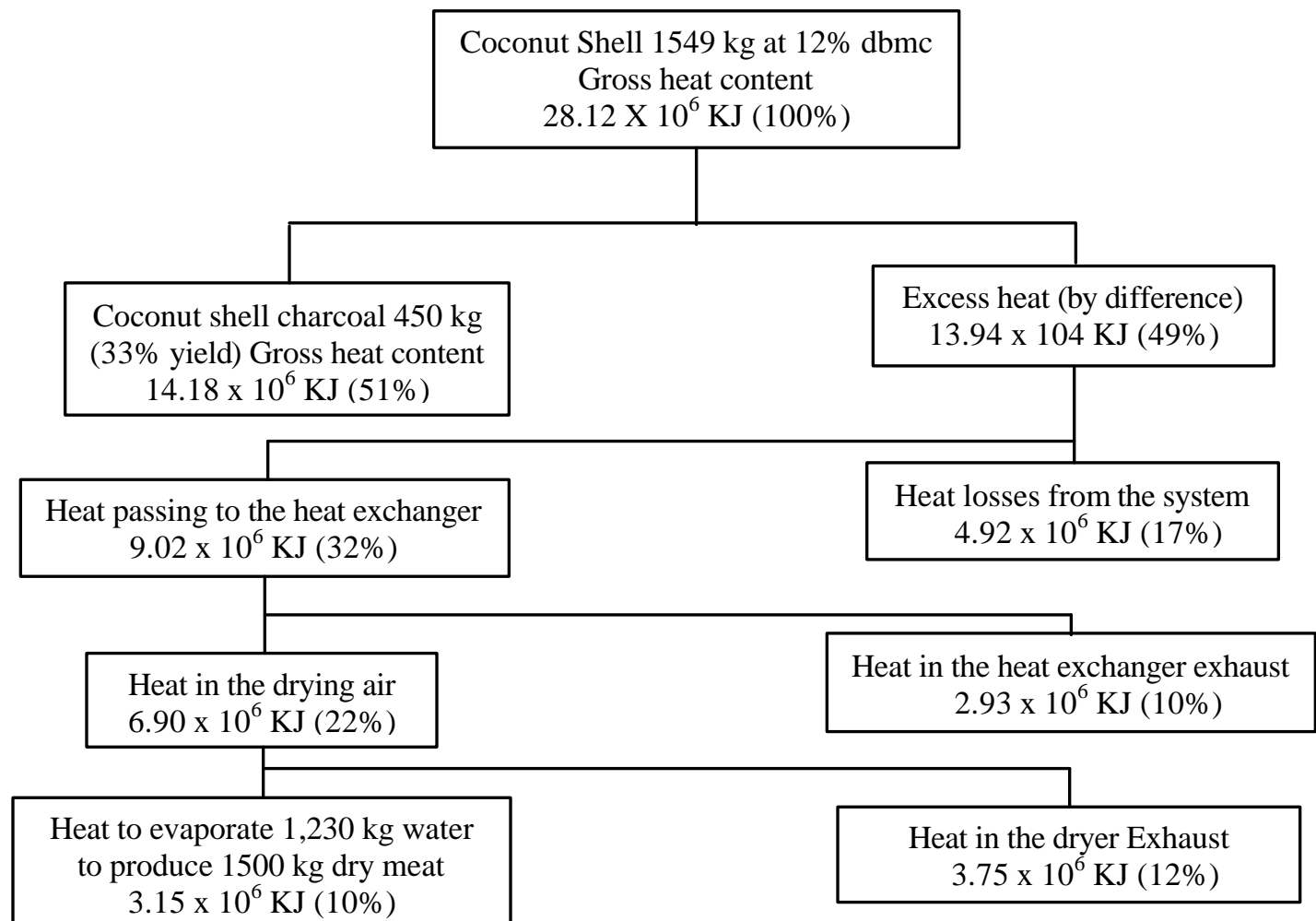

Figure 4. Typical overall heat balances for the production of cut dry coconut meat using a waste heat unit semi-automatic dryer system. 


\section{OBSERVATIONS AND DISCUSSION OF RESULTS}

\section{Technical}

The trials showed that the WHU-technology as developed can be used in the manufacture of coconut oil from freshly decorticated coconut kernels. Two WHUs could be operated in tandem to provide heat on a semi-continuous basis for drying the kernels from $45 \%$ down to approximately $4 \%$ moisture content using a semi-automatic dryer. To avoid holding the warm dry cut meat for long periods of time prior to passing through the oil expeller, the flow of material to and from the dryer had to be organized: this required good management of labour and raw material supplies and obviated the need to warm the charge prior to expelling. The effect of holding time, of both freshly cut kernels and warm dried coconut meat, on oil and coconut cake quality was not studied, but steps were taken to keep the times to below two hours. This aspect would need to be considered in commercial operations and in view of the possibility of long holding times adversely affecting product quality semi-continuos operation is recommended.

The removal of PAHs which is often necessary in the refining of coconut oil is expensive. However, the indirect drying of the cut coconut meat using the furnace/heat exchanger eliminates the contamination of the product with polyaromatic hydrocarbons; the quality of the coconut cake produced will also be similarly enhanced.

The throughput of the dryer was found to, be about 0.4 tonnes of dry cut copra product per hour using the traditional oil process compared to 0.15 tonnes using freshly cut coconut meat at 45 $\%$ moisture content for the "new oil process". Nevertheless the process system was still considered an improvement because it saved the coconut shell (amounting to $50 \%$ of the available shell) plus the wood fuel used in the traditional oil process. In addition the system also provided good quality charcoal. In summary, one tonne of dry coconut meat produced approximately 0.65 tonnes of oil and 0.35 tonnes of coconut cake: associated with this 0.3 tonnes of charcoal were produced. The oil content in the pressed cake was approximately 10 to $11 \%$ on a dry basis thus giving a total oil extraction of $94 \%$ of that in the original feedstock. In the case of the traditional method similar quantities of oil and copra cake, but of variable quality, were manufactured. Moreover only 0.15 tonnes of charcoal were produced from the shell and an additional 0.15 tonnes of fuelwood were consumed.

\section{Economic}

Based on the results of preliminary trials, an economic comparison of the production of oil via the traditional process using smoke-kilns with the new method where the kernels are decorticated (by hatcheting) and the freshly macerated nut is dried in a semi-automatic dryer prior to oil expelling was carried out (U V H Perera, 1989). For this, the two processes starting from the purchase of dehusked coconuts through to the production of oil were compared. The system discussed was based on the use of the standard capacity (1.5 tonnes shell) WHU and the semiautornatic dryer system used in Sri Lanka. Each semi-automatic dryer could produce approximately 3 tonnes of dry coconut meat per day when fired by two WHUs with each unit operated alternately on a 10 to 11 hour firing cycle.

Alternative systems could include a scaled-up WHU with a 3.4 tonne shell capacity and a 12 hour firing cycle which has also, been developed; its application has been discussed elsewhere (Breag and Joseph, 1989). The scale and type of operation required will of course be dependent on the specific requirements but it should be borne in mind that the standard WHU matches the requirements of the semi-automatic dryer and the scaled-up WHU twice the heat requirements. There is also scope for providing herat to dual-fuel boiler systems for process heat and this is another route by which the WHU technology may be applied. 
It is important to note that although many desiccated coconut millers also have copra curing and oil expelling facilities, the majority of the copra produced by estates and smallholders is channeled through the 125 oil mills in Sri Lanka. These mills are the main potential sites for the application of the WHU technology to produce oil by the "new oil process' using freshly comminuted coconut kernel. Sri Lanka has a large over-capacity to produce oil - which arises partly from the need to cope with peak production periods during May, June and July. The mills therefore operate at well below their optimal levels of production. In the comparison the large over-capacity of the oil processing plant - as it is common to both the new and traditional process - was, taken as standing capacity. In the study the smoke-kilns for curing the copra and the extra semi-automatic dryers required for the traditional and new process respectively were taken into, account in the economic analysis. It was concluded that for a daily output of 6.5 tonnes of oil and 3.5 tonnes of copra cake the incremental investment of the new process was Rs 1.8 million higher; but it was recoverable in 8 to 9 months. This was based on a 200 day per annum operation. Even if the new process was operated at 50\% capacity the total incremental investment would be recovered in 16 months.

\section{CONCLUSIONS}

The preliminary trials have shown that the application of the WHU technology for the production of oil by the "new oil" process is an attractive commercial proposition. The advantages of the widespread adoption of the process briefly would be the production of both a good quality coconut cake free of aflatoxin and an oil with a low free fatty acid content and free of PAHs. This would result in a marked reduction in oil refining costs and in the risk to health stemming from the consumption of contaminated products. Moreover the use of coconut shell-a by-product of the coconut industry instead of wood as fuel source would reduce the pressure on an increasingly scarce resource and in many cases save on the import of costly fossil fuels. In addition the maximization of the use of coconut shell for charcoal production would also enhance foreign exchange earnings through the export of charcoal or activated carbon prepared from it widespread adoption of the technology in coconut countries would consequently result in gains to both the producers and the national economies.

There is scope for the application of the "new oil process" as outlined above in many of the coconut growing countries and its widespread adoption is recommended. The process discussed may have to be adapted to meet local requirements but there is considerable scope for further technical and financial evaluation of the process on the commercial scale; and further results on the work are still to be collected. Nevertheless the process offers sufficient promise for its adoption to be encouraged, albeit cautiously, provided careful consideration is given in each case to the technical and economic aspects.

\section{ACKNOWLEDGEMENTS}

The authors acknowledge assistance provided by colleagues in both the CDA and the NRIparticularly Mr S. B. Ratnayake and Mr. U. V. H. Perera in the analysis of the products and financial appraisal of the results respectively. The invaluable assistance provided by staff and managers, at the mills - Mahandragahamulla, Megalle and Pothipeyeya where the initial evaluation trials were carried out and subsequently at Marawila Co-operation Mills is also recognized. The constructive c6mments of Dr R Harris of NRI were particularly helpful in the preparation of the paper. 


\section{REFERENCES}

BREAG, G R A P HARKER and A SMITH 1985. A case study of the TDRI carbonization and waste heat recovery unit: techno-economic evaluation of the use of a prototype unit for the carbonization of coconut shells in Sri Lanka. Trop Sci 25: 165-187.

TILLEKERATNE H A 1989. Transfer of coconut shell carbonization/waste heat recovery technology into the commercial sector in Sri Lanka. Report of the APCC/CDA/ODNRI Regional Workshop on waste heat recovery technology in coconut processing. Annex 1:65-72.

BREAG G R and P G JOSEPH 1989. The development and testing of the ODNRI coconut shell carbonisation/waste heat recovery unit. Report of the APCC/CDA/ODNRI Regional Workshop on waste heat recovery technology in coconut processing. Annex 1:51-64.

PERERA U V H 1989. Financial and economic appraisal of the application of coconut shell carbonization/waste heat recovery in coconut processing in Sri Lanka. Report of the APCC/ CDA/ODNRI Regional Workshop on waste heat recovery in coconut processing. Annex 1:91-104.

CECOCO 1968. Fresh coconut oil expelling unit. Circular No 757: 1-3. 